\title{
Improving the quality of delirium practices in a large Australian tertiary hospital: an evidence implementation initiative
}

\author{
AUTHORS \\ SIOBHAN CODY RN BN ${ }^{1}$ \\ LUCYLYNN LIZARONDO PhD² \\ ALEXA MCARTHUR RN RM MPHC MClinSc ${ }^{2}$ \\ AMY BARZEN RN BN(Hons) GCertClinN ${ }^{1}$ \\ CHRIS LADERA RN BSc MN GCertCritCare ${ }^{1}$ \\ SERAFINA LEVAK RN BN GCertCancer/ \\ Palliative Care ${ }^{1}$ \\ BETH MCALARY RN BN MEmergN ${ }^{1}$ \\ OLIVIA MISA RN BN ${ }^{1}$
}

MARIA SENATORE RN BScNursing CertGenNursing

GCertOncNursing GDipPallCare MClinNursing

(ClinicalNursing\&Teaching) ${ }^{1}$

CHRYSAFI TSIGOUNIS RN BN ${ }^{1}$

JOANNE TAYLOR RN BN GCertDiab MScDiab ${ }^{1}$

ANNA THORNTON RN MN ${ }^{1}$

1 St Vincent's Hospital Sydney, New South Wales, Australia

$2 \mathrm{JBI}$, University of Adelaide, South Australia, Australia

\section{CORRESPONDING AUTHOR}

LUCYLYNN LIZARONDO JBI, University of Adelaide, South Australia, Australia

Email: lucylynn.lizarondo@adelaide.edu.au

\section{ABSTRACT}

Objective: The aim of the evidence implementation initiative was to improve the quality of care delivered to hospitalised patients at risk of, or with, delirium through the implementation of best practice recommendations.

Background: Delirium is a prevalent serious medical condition that remains unrecognised or misdiagnosed in acute hospitals and is therefore left untreated. This paper reports on a hospital-wide quality improvement project which was undertaken in recognition of the Australian Delirium Clinical Care Standard and as a response to the cumulative rate of hospital-acquired delirium within a health organisation in New South Wales, Australia.

Methods: The quality improvement project used the JBI (formerly known as Joanna Briggs Institute) evidence implementation framework. Briefly, the $\mathrm{JBI}$ evidence implementation approach is grounded in the audit, feedback and re-audit process along with a structured process for the identification and management of barriers to compliance with recommended clinical practices. Twelve nurses, who received support from external facilitators (implementation researchers), acted as delirium champions.

Results: Baseline audit of 143 patient notes showed poor compliance (range 6\% - 67\%) to recommended practices relating to screening, assessment, prevention and management of delirium. Barriers analysis revealed nurse-related (eg. lack of knowledge) and organisational level factors (e.g. absence of a hospital-wide policy/procedure for delirium management). A multicomponent strategy was implemented by all delirium champions in their respective units/wards. Follow-up audit of 151 patient notes demonstrated significant improvements in compliance with best practice recommendations for all aspects of delirium care. 
Discussion: The quality improvement activity highlighted that education remains one of the most important and critical first steps in facilitating change in clinical practice. Critical to the success of the project was the collaborative approach of the delirium champions across various specialties, which allowed for the sharing of expertise, knowledge and consensus-based decision making. The facilitation provided by the delirium champions and external facilitators was also a vital ingredient for the successful implementation of evidence-based practices.

Conclusion: The quality improvement activity has improved nurses' screening and assessment of patients at risk of or with delirium, leading to improvements in its prevention and management. Collaborative efforts within the organisation facilitated the development of a standardised, evidence-based tool for delirium screening, assessment, prevention and management, and staff education resources. Partnership with patients and/ or their families through education remains an area for ongoing improvement, as with discharge planning for patients with current or resolved delirium.
What is already known about the topic?

- Delirium care is a major challenge among healthcare practitioners and therefore the condition remains prevalent in many acute hospitals. In Australia, delirium has been identified as a high priority area for quality improvement. The Australian Commission on Safety and Quality in Health Care released the Delirium Clinical Care Standard to ensure that patients at risk of delirium are identified early and receive preventative strategies, and that those with delirium receive optimal treatment to address their condition.

What this paper adds:

- This paper offers a detailed approach for evidence implementation to improve the quality of care delivered to hospitalised patients at risk of or with delirium. Key enablers were strong leadership support, sharing of experiences and knowledge, and the collective effort to problem solve and develop tools and resources for delirium.

Keywords: Delirium, evidence implementation, quality improvement, facilitation, audit and feedback

\section{BACKGROUND}

Delirium is a serious medical condition that can develop in hospitalised patients, particularly among older individuals over the age of 65 , palliative care populations, oncology patients, and individuals who have undergone transplant or major surgical procedures. ${ }^{1-3}$ Over $30 \%$ of hospitalised patients over 65 years of age will experience delirium in the medical ward setting and up to $88 \%$ of inpatients with advanced cancer. ${ }^{4,5}$ Hospitalised patients who develop delirium are at an increased risk of serious adverse outcomes including long-term functional and cognitive decline, increased risk of falls and harm from falls, and medical complications, which can then lead to prolonged hospital stays, need for institutional care and reduced quality of life. ${ }^{1,6-8}$ Previous studies have shown an association between delirium and premature death, with mortality rates ranging between 22 and $76 \%$ for those who developed delirium during hospitalisation. Delirium also imposes significant financial burden in the health system. ${ }^{9,10}$ In Australia, for example, the total cost of delirium was estimated at AUD $\$ 8.8$ billion in 2016-2017. ${ }^{10}$ Given the significant morbidity and mortality, and the associated economic burden, it is important that delirium is identified early so that appropriate management and preventive measures can be implemented.
Delirium is a medical emergency, management of which requires early detection, identification of the cause and management of symptoms. The emphasis is on primary prevention using multicomponent, non-pharmacological interventions targeted to high-risk patients. ${ }^{11,12}$ Various screening instruments, such as the Confusion Assessment Method (CAM), 4As Test (4AT), Delirium Triage Screen (DTS), Delirium Rating Scale (DRS) and Nursing Delirium Screening Checklist (NuDESC), have been developed to identify high-risk patients as well as diagnose and rate the severity of delirium. ${ }^{13}$ Once delirium is detected, a comprehensive assessment is required and management strategies implemented. These include removal and/or treatment of causative factors and in the first instance, management of symptoms using non-pharmacological approaches, reserving pharmacological interventions only where required. Typically, the management of delirium involves a multicomponent approach that includes reorientation, adequate hydration and nutrition, sleep promotion, early mobilisation, reduction of psychoactive drugs and optimising use of vision and hearing devices. ${ }^{12}$ It also requires an interdisciplinary approach that includes doctors, nurses and rehabilitation therapists along with well-informed and engaged families or caregivers. Families or caregivers, when provided with adequate information about the nature of delirium, symptoms and their integral role in the prevention 
and management of delirium, can significantly assist in enabling healthcare professionals to provide patient-centred delirium care. ${ }^{14}$ Patients with delirium require close clinical monitoring to ensure their safety, prevent complications, such as falls and pressure injuries, and to avoid emergence of factors that can worsen the delirium. ${ }^{15}$

Despite the high prevalence and associated adverse outcomes, and the potential to prevent occurrence, delirium remains unrecognised or misdiagnosed in acute hospitals and may therefore be left untreated. ${ }^{16}$ Recent studies suggest that between 24 and $61 \%$ of hospitalised patients with delirium were undiagnosed and only about $13.6 \%$ of cases received a comprehensive care plan. ${ }^{7,17,18}$ A recent study has also shown that there was significant variability in the way healthcare professionals respond to hospitalised patients with signs of delirium, that many actions were reactive instead of anticipative and preventive, and that the care provided was deficient and often not systematic and consistent. ${ }^{19}$ Delirium recognition and management appears to be a major challenge among healthcare practitioners and barriers to early detection exist at an individual and organisational level. Individual level barriers consist of lack of education and awareness of delirium, ${ }^{20-23}$ perception that it is not a priority, ${ }^{20}$ and lack of confidence with delirium assessment. ${ }^{21}$ Organisational barriers include a lack of guidelines or system integration translating delirium knowledge into the workplace, ${ }^{22}$ lack of locally agreed screening, assessment and diagnostic tools,,$^{22,23}$ the low priority assigned to delirium management, ${ }^{20}$ perception of being an 'orphan' condition (i.e. delirium does not belong to a specific specialty), ${ }^{20}$ heavy workload, ${ }^{22}$ and lack of leadership support. ${ }^{21}$

Within Australia there has been a growing awareness and concern about delirium, with delirium being identified by the Australian Commission on Safety and Quality in Health Care (ACSQHC) as a high priority area for quality improvement. The Commission established the Clinical Care Standards program to develop clinical care standards on health conditions that would benefit from a national coordinated approach. In 2016, the ACSQHC released the Delirium Clinical Care Standard to ensure that patients at risk of delirium, during their hospital admission, are identified early and receive preventative strategies. ${ }^{16}$ The Standard also ensures that patients with delirium at the time of presentation to the hospital receive optimal treatment to address their condition.

The quality improvement activity reported in this paper was undertaken in recognition of this Standard and as a response to the cumulative rate of hospital-acquired delirium within the health organisation. The project was conducted in a 36o-bed metropolitan tertiary hospital in New South Wales (NSW), Australia. In 2018, 299 episodes of hospital-acquired delirium were recorded in the facility. ${ }^{24}$ Rate of hospitalacquired delirium for the 2018/19 financial year was 8.1 occasions per 1,0oo separations (admissions). ${ }^{24}$ This rate was 3.0 occasions per 1,00o separations higher when compared to the NSW Hospital Peer Group. ${ }^{24}$ Prior to undertaking the quality improvement activity, the organisation had already identified the following issues that impact on their delirium practices: a general lack of knowledge about delirium and its management, lack of a locally agreed screening and assessment tool, and absence of a hospital-based policy and procedure for screening, assessment, prevention and management of delirium. These were the impetus for change and prompted the nursing department of the hospital to launch a hospital-wide quality improvement project to facilitate the implementation of best practice in delirium care and optimise hospitalised patient outcomes.

\section{AIMS OF THE QUALITY IMPROVEMENT PROJECT}

The overall aim of the project was to improve the care delivered to hospitalised patients at risk of, or with, delirium through the implementation of evidence-based delirium practices. There were three specific objectives:

- To establish baseline practice in terms of delirium screening, assessment, prevention and management

- To develop and implement strategies for improving delirium practices based on identified barriers to compliance with best practice recommendations

- To evaluate changes in delirium practices following the implementation of identified strategies

\section{METHODS}

\section{ETHICS}

The project was registered as a quality improvement activity within the hospital, and therefore did not require ethical approval.

\section{DESIGN}

This quality improvement project used the JBI (formerly known as Joanna Briggs Institute) Evidence Implementation framework. ${ }^{25}$ Briefly, the JBI Implementation approach is grounded in the audit, feedback and re-audit process along with a structured approach to the identification and management of barriers to compliance with recommended clinical practices. It consists of seven stages including: (1) identification of practice area for change, (2) engaging change agents, (3) assessment of context and readiness to change (i.e. situational analysis), (4) review of practice (i.e. baseline audit) against evidence-based audit criteria, (5) implementation of changes to practice, (6) re-assessment of practice using a follow-up audit, and (7) consideration of the sustainability of practice changes. 


\section{PROCESS}

From the commencement of the project there was strong senior leadership support from the Executive team who consistently demonstrate commitment to continuous quality improvement and evidence-based health care. Nursing unit managers were actively engaged and agreed to ensuring protected time for staff involved in leading the project.

Following the identification of delirium as a priority area for improvement in the hospital, a call for expressions of interest were sought from registered nurses who were interested in acting as a change agent for each participating unit/ward. To be eligible, nurses (referred to as delirium champions) had to have a strong interest in delirium care and possess leadership skills. Their role as change agents involved participating in the JBI Clinical Fellowship Training Program, ${ }^{26}$ organising a project team, developing a quality improvement project plan and leading the project at their local unit/ward level. Participating wards were known to represent patient groups at high risk of developing delirium and included: an emergency department, a specialty medical unit (comprising specialties including oncology, immunology, infectious diseases and other general medical specialties), haematology and bone marrow transplant, palliative care, heart and lung stream critical care wards, rehabilitation, mental health emergency services and an acute aged care ward.

As part of the JBI Clinical Fellowship Training Program, two experienced evidence implementation researchers were assigned to the project as 'facilitators' to assist with the development of local ward project plans, ensure projects progressed as planned and provide feedback and as-needed support (e.g. access to evidence-based resources, data analysis) to delirium champions. Monthly meetings between delirium champions and facilitators were organised to report project updates and discuss any issues that might impact the project.

\section{DATA COLLECTION AND SAMPLING}

Prior to the baseline audit, delirium champions collectively performed a situational analysis via round table discussions, and considered the following: resource availability, interdisciplinary relationships, workplace culture, leadership support, communication systems for information exchange, knowledge and skills of healthcare staff and commitment to quality management. These confirmed the organisation's overall readiness for change in terms of delirium practice.

Best practice recommendations from delirium clinical guidelines and the ACSQHC Delirium Clinical Care Standard were summarised and distilled into audit criteria (Table 1), ${ }^{16,27-33}$ which served as the basis for undertaking the clinical audit (both for baseline and follow-up). Following the development of audit criteria, an audit guide was developed to ensure standardised and reliable data collection for each criterion. Delirium champions and the facilitators collaborated to determine the source of data, sample size and how each criterion was to be measured to determine compliance. For validation, the delirium champions pilottested the audit guide, and revisions to the guide were made accordingly after the pilot testing.

\section{TABLE 1: AUDIT CRITERIA FOR BASELINE AND FOLLOW-UP AUDIT}

\begin{tabular}{|c|c|}
\hline 01 & $\begin{array}{l}\text { Patients presenting to the hospital with one or more risk } \\
\text { factors for delirium are screened using a validated tool. }\end{array}$ \\
\hline 02 & $\begin{array}{l}\text { Patients presenting to the hospital with one or more key } \\
\text { risk factors for delirium (and/or their carers or healthcare } \\
\text { providers) are asked about any recent changes in the } \\
\text { patient's behaviour or thinking. }\end{array}$ \\
\hline 03 & $\begin{array}{l}\text { Patients who screened positive for cognitive impairment and/ } \\
\text { or demonstrated an acute change in behaviour are assessed } \\
\text { for delirium using a validated tool. }\end{array}$ \\
\hline 04 & $\begin{array}{l}\text { Health professionals discuss delirium risk with the patient } \\
\text { and their carer. }\end{array}$ \\
\hline 05 & $\begin{array}{l}\text { Carers of patients who are at risk of delirium are provided } \\
\text { information about delirium and strategies to prevent/manage } \\
\text { it. }\end{array}$ \\
\hline 06 & $\begin{array}{l}\text { Patients identified at risk of delirium are offered interventions } \\
\text { to prevent delirium. }\end{array}$ \\
\hline 07 & $\begin{array}{l}\text { Patients identified at risk of delirium are monitored regularly } \\
\text { for changes in behaviour, cognition and physical condition. }\end{array}$ \\
\hline 08 & $\begin{array}{l}\text { Patients with delirium undergo a comprehensive assessment } \\
\text { to identify possible causes of delirium. }\end{array}$ \\
\hline 09 & $\begin{array}{l}\text { Patients with delirium receive a set of interventions to } \\
\text { treat the cause/s of delirium, as identified during the } \\
\text { comprehensive assessment. }\end{array}$ \\
\hline 10 & $\begin{array}{l}\text { Patients with delirium are screened to identify and manage } \\
\text { the risk of falls. }\end{array}$ \\
\hline 11 & $\begin{array}{l}\text { Patients with delirium are screened to identify and manage } \\
\text { the risk of pressure injuries. }\end{array}$ \\
\hline 12 & $\begin{array}{l}\text { Patients with delirium who are distressed receive non- } \\
\text { pharmacological management as first-line therapy, and their } \\
\text { cause of distress investigated. }\end{array}$ \\
\hline 13 & $\begin{array}{l}\text { Prior to discharge, patients with current or resolved delirium } \\
\text { (and/or their carers) participate in the development of, and } \\
\text { receive, an individualised care plan. }\end{array}$ \\
\hline
\end{tabular}

The baseline and follow-up audit was performed over threemonth periods (April - June 2019 and Oct - Nov 2019) using the Clinical Excellence Commission's Quality Auditing Reporting System (QARS), which is a web-based audit hosting platform. Baseline and follow-up audit data were collected from clinical notes of patients admitted in the participating wards/units. A staff survey was also administered at baseline to determine nurses' knowledge and confidence in managing patients with delirium. The survey consisted mostly of Likert-type questions, with a few that asked the staff to list their answers (e.g. commonly used strategies for delirium). In addition, the rate of hospital-acquired delirium in the hospital was reviewed before and after the project, and compared with peer hospitals' rate of delirium. 


\section{DATA ANALYSIS}

Descriptive analyses of baseline and follow-up compliance data, using frequency counts and percentages, were conducted using Microsoft Excel.

\section{SUSTAINABILITY PLANNING}

After the follow-up audit, delirium champions convened with the 'facilitators' to discuss strategies for ensuring practice improvements which were sustainable and plan for future audits. Areas of focus for further improvements in delirium care were identified and prioritised.

\section{RESULTS}

\section{CHARACTERISTICS OF THE DELIRIUM CHAMPIONS}

A total of 12 nurses participated in the project: four clinical nurse educators, two clinical nurse consultants, two registered nurses, two clinical nurse specialists, one nurse manager and one acting nurse unit manager.

\section{BASELINE AUDIT}

Baseline audit data were collected from the clinical notes of 143 patients admitted in the following wards/units: haematology and transplant unit $n=10$; speciality medical unit $n=10$; emergency department $n=14$; rehabilitation units $n=26$; mental health unit $n=4$; palliative care unit $n=$ 16; acute aged care unit $n=20$; surgical unit $n=8$; coronary care unit $n=16$; cardiac surgery unit $n=10$; neurology and stroke unit $n=10$. At baseline, 172 nursing staff completed the survey. Clinical notes selected for audit contained either a delirium diagnosis code (based on the International Statistical Classification of Diseases and Related Health Problems, Tenth Revision, Australian Modification) or one of the delirium key risk factors outlined within the ACSQHC Delirium Clinical Care Standard.$^{16}$ Where possible, half of the clinical notes audited in each ward or unit were coded with a delirium diagnosis.

Initial compliance to the majority of audit criteria $(n=10 / 13)$ was poor (range 6-67\%), as shown in Figure 1; compliance was considerably higher $(82-83 \%)$ for other criteria relating to monitoring of at-risk patients, and screening for and management of risk for falls and pressure injuries.

\section{BARRIERS TO COMPLIANCE WITH RECOMMENDED DELIRIUM PRACTICES}

Following the baseline audit, delirium champions held group sessions with their project teams to identify barriers to compliance with the recommended practices (as reflected in the audit criteria). Project teams consisted of key stakeholders from the specific wards including nursing staff, physiotherapists, occupational therapists, geriatric physicians and specialists. Barriers analysis revealed nurse-related and organisational level factors that hindered compliance to recommended practices in delirium care. Nurses generally lacked confidence in their assessment and management skills with respect to delirium. Survey responses indicated that they felt they had limited knowledge about delirium and its management, including screening, assessment, prevention and treatment. There was also a general lack of awareness regarding information resources about delirium and support for patients and their families, and a lack of access to these resources. On an organisational level, the lack of a locally agreed standardised tool to facilitate screening, assessment, prevention and management of delirium and the absence of a hospitalwide policy and procedure for delirium management were identified as key barriers.

\section{MULTI-COMPONENT STRATEGY}

The delirium champions convened to discuss strategies which could be implemented hospital-wide, to provide a collaborative approach to the development of resources. Given the multifactorial causes of non-compliance to recommended practices, a multicomponent strategy was implemented by all delirium champions in their respective units/wards. Table 1 outlines the different strategies targeted to the identified barriers.

\section{TABLE 1: SUMMARY OF STRATEGIES ADDRESSING THE IDENTIFIED BARRIERS TO COMPLIANCE WITH RECOMMENDED DELIRIUM PRACTICES}

\begin{tabular}{|c|c|}
\hline $\begin{array}{l}\text { Barriers to compliance with } \\
\text { recommended practices }\end{array}$ & Strategies \\
\hline \multicolumn{2}{|l|}{ Health practitioner level } \\
\hline $\begin{array}{l}\text { - Lack of confidence and } \\
\text { limited knowledge about } \\
\text { delirium and its management } \\
\text { - General lack of awareness } \\
\text { regarding information } \\
\text { resources }\end{array}$ & $\begin{array}{l}\text { Education sessions and } \\
\text { resources for nursing and } \\
\text { allied health staff } \\
\text { - Delirium display boards/ } \\
\text { delirium brochures } \\
\text { - Other ward-specific strategies } \\
\text { (e.g. role-play sessions, } \\
\text { delirium prompt cards) }\end{array}$ \\
\hline \multicolumn{2}{|l|}{ Organisation level } \\
\hline $\begin{array}{l}\text { Absence of a hospital-wide } \\
\text { policy and procedure for } \\
\text { delirium management and } \\
\text { lack of a locally agreed } \\
\text { standardised tool for } \\
\text { screening, assessment, } \\
\text { prevention and management } \\
\text { of delirium }\end{array}$ & $\begin{array}{l}\text { Development, testing and } \\
\text { implementation of tool for } \\
\text { screening, assessment, } \\
\text { prevention and management } \\
\text { of delirium } \\
\text { - Development of a hospital- } \\
\text { specific policy and procedure } \\
\text { for delirium care } \\
\text { - Engagement with key } \\
\text { stakeholders }\end{array}$ \\
\hline
\end{tabular}

All strategies focused on improving health practitioners' knowledge about delirium screening, assessment, prevention and management, and increasing nurses' assessment of patients who might be at risk of developing delirium. To achieve these outcomes, the following strategies were implemented: 
- A standardised tool for screening, assessment, prevention and management of delirium (please contact authors for access to the tool): The delirium champions developed and tested a tool that addressed recommended practices for delirium screening, assessment, prevention and management. The tool was developed in collaboration with the hospital's 'Delirium and Cognitive Impairment Community of Practice,' which consists of a multidisciplinary group of experienced clinicians with a particular expertise in delirium. The tool comprised a validated screening and assessment tool (4AT), ${ }^{13}$ a list of preventative strategies as well as assessment and management strategies for those presenting with an acute delirium. The tool provided a one-stop resource for nurses involved in managing patients who might be at risk of delirium. In some wards/units, the tool was incorporated in ward admission packs for ready access as well as serving as a prompt for nursing staff to screen for risk of delirium when admitting a patient.

- A hospital-specific policy and procedure for delirium care

- Education for nursing and allied health staff: a standardised PowerPoint presentation on delirium was developed by the aged care clinical nurse consultant. This included information related to the prevalence, types, risk factors and causes of delirium, including principles and strategies for screening, assessment, prevention and management of delirium. Additional information were included in the face-to-face in-services to tailor the training to participating specialty units. Education on the use of the delirium tool (mentioned above) was also provided to all relevant staff. Face-to-face sessions, which lasted from 30 minutes to an hour, were delivered over a 12-week period by the delirium champions and respective clinical nurse educators of the different clinical areas. During sessions, staff were encouraged to ask questions and were encouraged to seek further support if required. A total of 345 nurses ( $84 \%$ of the ward/unit workforce) and 20 occupational therapists (OT) (83\% of total OT workforce) were educated during the course of the project. Informal education was delivered to junior medical officers focusing on the tool and the role of medical officers in delirium prevention and management. As this was an informal process there were no records kept of attendance. A delirium folder containing the resources used in the education sessions and delirium brochures were ordered and organised to provide access to delirium information. Delirium information posters were also displayed on wards to reinforce the education provided during face-to-face sessions.

- Resources for patients: a delirium brochure developed by the Agency for Clinical Innovation (ACI) was included in admission packs for dissemination to patients and their caregivers. ${ }^{34}$ The brochure contains easy-to-understand information about the symptoms, causes and course of delirium, and how it can be managed.
- Display boards: The ACI delirium brochure and other delirium posters were used as reminders, provided ready access to information and raised delirium awareness. ${ }^{34}$ The ACI CHOPS sunflower was displayed at the patient's bedside to collect important patient-centred information about the patient that can help re-orientate those who might have cognitive impairment. 35

- Engagement with key stakeholders: flow manager discussed 'flagging' the high-risk patients on the patient flow portal in order to swiftly identify those patients at risk to nurse managers in charge of bed allocations and movements.

- Other ward-specific strategies: Staff of the aged care ward used ID flip cards that included best practice recommendations for delirium care. A role-play session was also conducted in this ward to demonstrate that the time requirements for completing the delirium tool is short and reasonable, which was contrary to the staffs' perceived burden of completing another assessment/form. To improve the orientation of their patients, the palliative care ward sought funding for the purchase of digital clocks and calendars. In the emergency department, Six-Minute Intensive Training tools were distributed to staff during morning or evening shift safety huddles and lanyard Delirium Risk prompt cards were also provided to all nursing and medical staff.

\section{FOLLOW-UP AUDIT VERSUS BASELINE AUDIT}

Follow-up data were collected from clinical notes of 151 patients (haematology and transplant unit $n=10$; speciality medical unit $n=10$; emergency department $\mathrm{n}=20$; rehabilitation units $\mathrm{n}=9$; mental health unit $\mathrm{n}=$ 15; palliative care unit $n=15$; acute aged care unit $n=20$; coronary care unit $n=20$; cardiac surgical unit $n=24$; surgical unit $\mathrm{n}=8$ ). Clinical notes were selected for audit using the same methodology outlined above in baseline audit. The compliance rate for all audit criteria improved (as shown in Figure 1) following the implementation of strategies.

\section{DELIRIUM RATES}

The rate of hospital-acquired delirium at this tertiary hospital decreased post implementation of the quality improvement activity. Rate of hospital-acquired delirium for the 2019/2O financial year was 7.1 occasions per 1,0oo separations (admissions), compared to 8.1 the previous 2018/19 financial year. ${ }^{24}$ This equates to a $12.3 \%$ decrease pre-implementation compared to post-implementation.

Further, the difference in rate of hospital-acquired delirium between the tertiary hospital and its NSW Hospital Peer Group was 3.0 occasions per 1,000 separations in 2018/19. ${ }^{24}$ This difference narrowed to 1.7 occasions per 1,000 separations in the post implementation year 2019/20. 


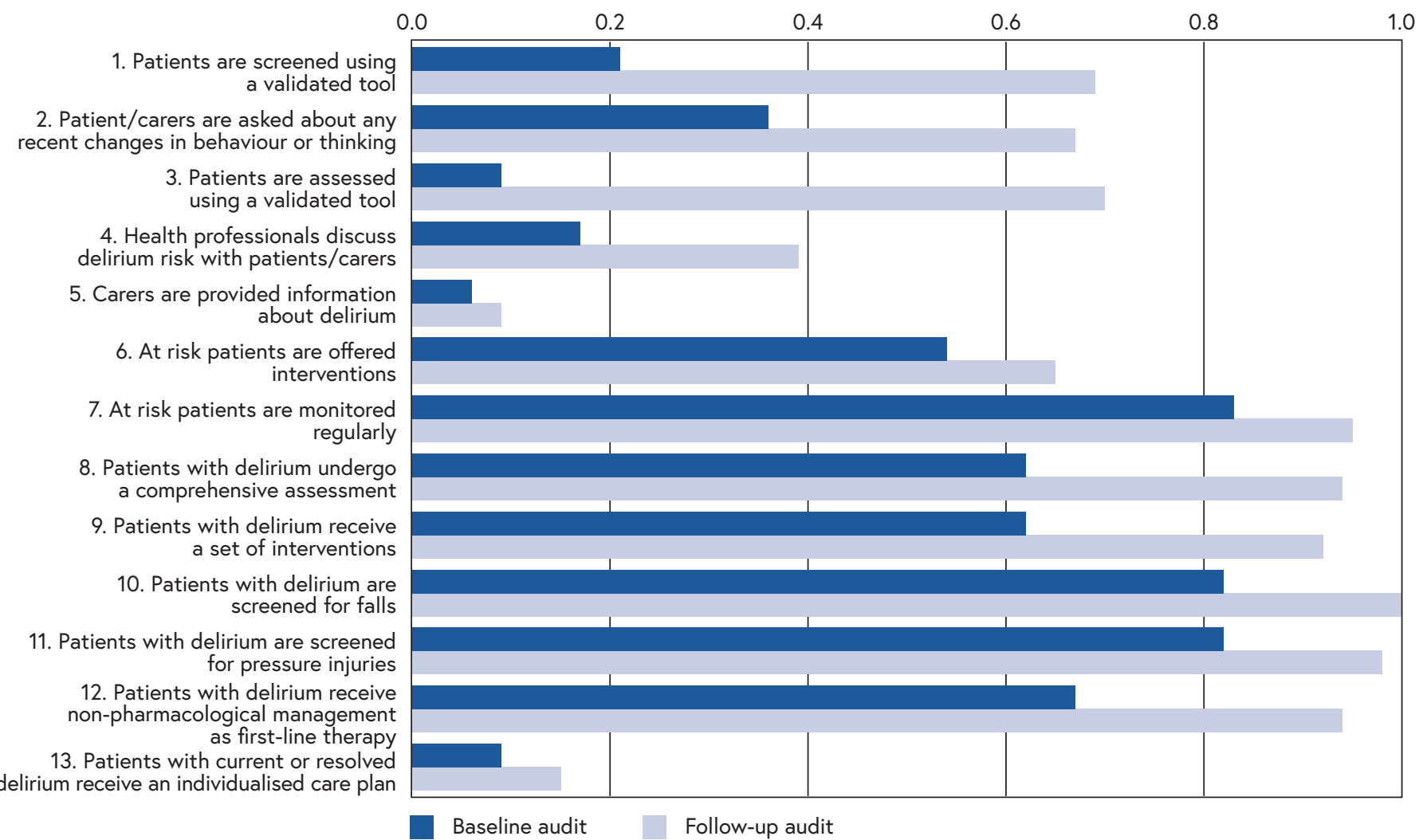

FIGURE 1: BASELINE AND FOLLOW-UP COMPLIANCE WITH AUDIT CRITERIA

\section{DISCUSSION}

This quality improvement activity achieved its aim of improving the care delivered to hospitalised patients at risk of or with delirium, as demonstrated by increased compliance to recommended practices for delirium care. As a result of this activity, a standardised tool for delirium screening, assessment, prevention and management has been implemented in the hospital along with a locally agreed policy and procedure for delirium care. This resource was key to increasing screening and assessment of patients at risk of developing delirium, which prompted early intervention for preventative measures. Also critical to the success of the project was the collaborative approach of the delirium champions across various specialties, which allowed for the sharing of expertise, knowledge and consensus-based decision making. Partnership with patients and/or their families through education remains an area for ongoing improvement, as with discharge planning for patients with current or resolved delirium.

One of the vital ingredients for successful implementation of evidence into practice is 'facilitation.' Facilitation has been defined as 'a technique by which one person makes things easier for others' ${ }^{36}$ and is both a process and a role (facilitator). ${ }^{37}$ For this quality improvement activity, facilitation occurred internally via the delirium champions as well as externally through the facilitators who provided as-needed support to the champions. A core responsibility of the delirium champions was to drive the practice change and act as an ongoing resource person for the quality improvement activity. They also performed a range of other activities including education of staff about delirium, assessment of local practice through audits and barrier analysis, evaluation of practice change, and peer support. On the other hand, external facilitators provided evidence implementation education and technical research support, and ensured the project was on track. These activities are congruent with the findings of previous studies on facilitation, which highlighted that successful facilitation efforts in health organisations involve both internal and external facilitation. ${ }^{88,39}$ As highlighted in the literature, internal facilitation capacity is critical in creating a sustainable infrastructure for implementation activities, while external facilitation is key for providing support to internal facilitators in creating organisational facilitation capacity..$^{40,41}$ This strategic partnership supports an integrated approach to promoting evidence-based practices, for which both implementation scientists and frontline clinicians agree is ideal for sustainable practice change. ${ }^{42,43}$

Effective health care delivery is highly dependent on teamwork that draws on the expertise of each team member and pooling this expertise to collectively deliver safe and high-quality health care. Key enablers for the current project were the constructive discussions, sharing of experiences and knowledge, and the collective effort to problem solve and develop tools and resources for delirium practice 
improvements. The complex nature of delirium suggests that the task required to improve clinical practice is also complicated and requires a team effort. One of the key strategies for this quality improvement activity was the delirium screening and assessment tool also outlining preventative and treatment interventions. The tool was developed and validated collectively by the delirium champions, with input from frontline clinicians and delirium specialists. This level of engagement by relevant stakeholders within the organisation highlighted a sense of ownership and a strong commitment to improve delirium practices. This is in line with the findings of a recent study which suggested that delirium care requires a 'choreographed dance of teamwork and integration across services' in order to be effective. ${ }^{44}$ Psychological and organisational research also supports the notion that improving teamwork is a viable strategy for enhancing care coordination and optimising the quality of health care outcomes. 45

This quality improvement activity highlights that education remains one of the most important and critical first steps in facilitating change in clinical practice. Staff feedback at the commencement of the project identified that 'risk for delirium' was not common terminology, with only a few clinicians understanding the plethora of risk factors associated with this condition. Assessment for delirium was also unheard of by many nursing staff, with only a select few units, such as the aged care ward and the intensive care unit, performing routine cognitive assessments as part of their preventative and diagnostic pathways. Discussions about delirium risk and prevention were essentially absent from the nursing and medical handover terminology within the organisation. When it did occur, delirium was often informally diagnosed on the basis of a presenting history, collateral information from family members, carers or general practitioners, and relevant signs and symptoms. It is well-recognised in the delirium literature that informal, clinical delirium rating is inadequate for accurately detecting delirium. ${ }^{4}$ It is for these reasons that education was the key strategy required to improve the current delirium practice. Research evaluating the effect of educational interventions on delirium recognition showed improved staff performance and adherence to delirium protocols. ${ }^{47,48}$ Literature also identified effective enabling and reinforcing strategies for education and included the use of champions, feedback on staff performance and use of protocols, which were similar to the approaches used in the current project. Therefore, it appears that the most effective educational approaches to improving delirium practices are multifaceted and include other enabling strategies in addition to knowledge transmission.

Person-centred care is a hallmark of good quality clinical practice. It relies on reciprocal communication between the patient (and/or their family) and health professionals, and recognises the uniqueness and value of the individual.49,50 Implementation of the delirium tool enabled nurses an opportunity to obtain relevant information from the patient's family that could then be used to individualise the care provided. However, it remains unclear whether nurses actually engaged and initiated discussions with patients and/ or their families when they provided them with educational/ information pamphlets or brochures. Patient and/or family participation in the development of care plans were also suboptimal. As with other conditions, it is important to ensure that patients and their families establish a meaningful interaction with their health practitioners, and are able to understand the information they receive and are provided opportunities to clarify and ask questions. The literature suggests that, although it can be quite challenging, personcentred delirium care can be delivered effectively using context-informed strategies. ${ }^{49,51}$ The delirium champions have agreed that this should be the focus of their future audits, and consistent with the approach of the current project, addressing the factors that assist or hinder acceptance and implementation of person-centred care is a crucial step.

Although positive changes in delirium practice were achieved, there are still many areas of delirium care that are suboptimal and require attention. The reasons for this are likely multifactorial. Firstly, the documentation of some of the care provided to patients remains poor. For example, the delirium champions have observed that patients and carers were provided education by relevant staff, and yet there was poor documentation that this had taken place. Preventative measures such as regular mobilisation, orienting patients to time, place and person, and maintenance of hydration and nutrition, although common practice, were also not captured in patient records. Secondly, although the majority of relevant staff had received education, high staff rotation and employment of new staff meant that a number had not participated in any education session. Thirdly, it became apparent during data collection that some of the audit criteria required further clarification. For example, 'regular' monitoring for changes in behaviour, cognition and physical condition for patients at risk of delirium was interpreted in different ways by the data collectors. What constitutes as 'preventative strategies' was also raised by nurses, in that the tool which served as their one-stop resource did not have a comprehensive list of interventions. As such, some of the preventative measures that were administered to patients were not considered in the audit. Finally, there were a number of challenges experienced during the course of the project. Several other quality improvement initiatives occurred at the same time, which meant that gaining interest from staff who felt 'fatigued' with change was more arduous than expected. The introduction of the delirium tool was perceived by some staff as 'another piece of paper' that would take their time away from patient care needs, rather than a resource that could assist in decision making. Patients from culturally and linguistically diverse backgrounds were also a challenge as available patient and family resources were in English, and interpreters or family members that spoke English were not always readily available. 
There are limitations to this quality improvement project that need to be considered. Firstly, the timeframe of nine months for the project was relatively short. The sample used was small and may not be representative of the population of interest, and may not also reflect the seasonal variations that might have occurred in terms of patient characteristics. In addition, the time spent to implement all the interventions may not have been adequate to expect changes in clinical practice. There may also have been a Hawthorne effect, ${ }^{2}$ impacting on nurses' behaviour during the course of the project. Lastly, data for compliance with recommended practices were gathered exclusively from an audit of patient notes, which may not be sufficient to evaluate the effectiveness and success of the implementation strategies. In addition, no data were obtained directly from patients and/ or their families, which would have validated the compliance data related to patients/carers receiving education/ information and their participation in the development of an individualised care plan.

\section{CONCLUSION}

This quality improvement activity has improved nurses' screening and assessment of patients at risk of or with delirium, leading to improvements in its prevention and management. Collaborative efforts within the organisation facilitated the development of a standardised, evidencebased tool for delirium screening, assessment, prevention and management, and staff education resources, which improved nurses' knowledge and practice behaviour. However, there is still room for improvement particularly in areas related to patient and/or family education and participation, and discharge planning and care. Further audits will be undertaken in the future to explore these areas and determine sustainability of practice improvements.

Acknowledgement: Elizabeth Endean, Aged Care CNC, for contributing to the development of delirium educational resources. Julia Navarro RN and Danielle Austin RN for their contribution to the development of education, clinical audit and policy development. St Vincent's Curran Foundation for financial support of the Joanna Briggs Clinical Fellowship Program.

Funding Support: St Vincent's Curran Foundation funding of the Joanna Briggs Clinical Fellowship Program.

\section{REFERENCES}

1. Schubert $M$, Schürch $R$, Boettger $S$, Nuñez $D$, Schwarz $U$, Bettex $\mathrm{D}$, et al. A hospital-wide evaluation of delirium prevalence and outcomes in acute care patients - a cohort study. BMC Health Serv Res. 2018; 18(1): 550.

2. Vasilevskis EE, Han JH, Ely EW. Epidemiology and risk factors for delirium across hospital settings. Best Pract Res Clin Anaesthesiol. 2012; 26(3): 277-87.
3. Bellelli G, Morandi A, Di Santo S, Mazzone A, Cherubini A, Mosello E, et al. "Delirium Day": a nationwide point prevalence study of delirium in older hospitalized patients using an easy standardized diagnostic tool. BMC Med. 2016; 14: 106.

4. Ryan DJ, O'Regan NA, Caoimh R, Clare J, O'Connor M, Leonard $M$, et al. Delirium in acute hospital population: predictors, prevalence and detection. BMJ Open. 2013; 3(1):e001772.

5. LeGrand S. Delirium in palliative medicine: a review. J Pain Symptom Manage. 2012; 44(4): 583-94.

6. Sanchez-Hurtado L, Hernández-Sánchez N, Del Moral-Armengol M, Guevara-García H, García-Guillén F, Herrera-Gómez A, et al. Incidence of delirium in critically ill cancer patients. Pain Res Manag. 2018; 2018: 4193275.

7. Lange $P$, Lamanna M, Watson R, Maier A. Undiagnosed delirium is frequent and difficult to predict: results from a prevalence survey of a tertiary hospital. J Clin Nurs. 2019; 28(13-14): 2537-42.

8. Goldberg T, Chen C, Wang Y. Association of delirium with longterm cognitive decline: a meta-analysis. JAMA Neurol. 2020. Available from: https://doi.org/10.1001/iamaneurol.2020.2273

9. Leslie $D$, Inouye $S$. The importance of delirium: economic and societal costs. J Am Geriatr Soc. 2011; 59 (Suppl 2): S241-3.

10. Pezullo L, Streatfeild J, Hickson J, Teoderczuk A, Agar M, Caplan G. Economic impact of delirium in Australia: a cost of illness study. BMJ Open. 2019; 9: e027514

11. Martinez F, Tobar $C$, Hill N. Preventing delirium: should nonpharmacological, multicomponent interventions be used? A systematic review and meta-analysis of the literature. Age Ageing. 2014; 44(2): 196-204.

12. Morandi A, Mazzone A, Bernardini B, Suardi T, Prina R, Pozzi C, et al. Association between delirium, adverse clinical events and functional outcomes in older patients admitted to rehabilitation settings after a hip fracture: a multicenter retrospective cohort study. Geriatr Gerontol Int. 2019; 19(5): 404-8.

13. De J, Wand A. Delirium screening: a systematic review of delirium screening tools in hospitalized patients. Gerontologist. 2015; 55(6): 1079-99

14. Australian Commission on Safety and Quality in Health Care. A better way to care: safe and high-quality care for patients with cognitive impairment (dementia and delirium) in hospital actions for health service managers. Sydney; ACSQHC, 2014

15. Grover $S$, Avasthi A. Clinical practice guidelines for management of delirium in elderly. Indian J Psychiatry. 2018; 60(Suppl 3): S329-S340.

16. Australian Commission on Safety and Quality in Health Care Delirium clinical care standard. ACSQHC. Sydney. 2016.

17. Dela Cruz M, Fan J, Yennu S, Tanco K, Hin S, Wu J, et al. The frequency of missed delirium in patients referred to palliative care in a comprehensive cancer center. Support Care Cancer. 2015; 23(8): 2427-33

18. Praditsuwan R, Limmathuroskul D, Assanasen J, Pakdeewongse S, Eiamjinnasuwat W, Sirisuwat A, et al. Prevalence and incidence of delirium in Thai older patients: a study at general medical wards in Siriraj Hospital. J Med Assoc Thai. 2012; 95 (Suppl 2): S245-50

19. Johansson Y, Bergh I, Ericsson I, Sarenmalm EK. Delirium in older hospitalized patients-signs and actions: a retrospective patient record review. BMC Geriatr. 2018; 18(1): 43

20. Teodorczuk A, Reynish E, Milisen K. Improving recognition of delirium in clinical practice: a call for action. BMC Geriatr. 2012; 12: 55 
21. Rowley-Conwy G. Barriers to delirium assessment in the intensive care unit: a literature review. Intensive Crit Care Nurs. 2018; 44: 99-104.

22. Bozzo M. The barriers and enablers related to the early recognition of delirium in older palliative care patients - an integrative literature review. Aust Nurs Midwifery J. 2015; 23(3): 28-31.

23. LaMantia M, Messina F, Jhanji S, Nazir A, Maina M, McGuire $S$, et al. Emergency medical service, nursing, and physician providers' perspectives on delirium identification and management. Dementia (London). 2017; 16(3): 329-43

24. Clinical Excellence Commission. User manual: quality improvement data system V2.0 [intranet]. Clinical Excellence Commission. Sydney. 2018. [Cited 23 July 2020] Available from: https://gids.cec.health.nsw.gov.au

25. Munn Z, McArthur A, Porritt K, Lizarondo L, Moola S, Lockwood C. Evidence implementation projects using an evidencebased audit and feedback approach: the JBI Implementation Framework. In: Porritt K, McArthur A, Lockwood C, Munn Z (Editors). JBI Handbook for Evidence Implementation. JBI. 2020. [Cited 23 July 2020] Available from: https://doi.org/10.46658/ JBIMEI-20-03

26. McArthur A, Munn Z, Lizarondo L, Porritt K, Stephenson M, Stern $C$, et al. The ripple effect of evidence implementation: a descriptive evaluation of JBI's Evidence-based Clinical Fellowship Program. [E-pub ahead of print] JBI Evid Implement. 2020.

27. National Institute for Health and Care Excellence. Delirium: prevention, diagnosis and management - clinical guideline [CG103]. 2019. Available from: https://www.nice.org.uk/ guidance/cg103

28. Devlin J, Skrobik Y, Gelinas C, Nedham D, Slooter A, Pandharipande $\mathrm{P}$, et al. Clinical practice guidelines for the prevention and management of pain, agitation/sedation, delirium, immobility, and sleep disruption in adult patients in the ICU. Crit Care Med. 2018; 46(9): e825-e873.

29. Bush SH, Lawlor PG, Ryan K, Centeno C, Lucchesi M, Kanji S, et al. Delirium in adult cancer patients: ESMO Clinical Practice Guidelines. Ann Oncol. 2018; 29(Suppl 4): iv143-iv165.

30. American Geriatrics Society Expert Panel on Postoperative Delirium in Older Adults. American Geriatrics Society abstracted clinical practice guideline for postoperative delirium in older adults. J Am Geriatr Soc. 2015; 63(1): 142-50.

31. Marin T. Evidence Summary. Postoperative Delirium (Older People): Prevention and Management. The Joanna Briggs Institute EBP Database, JBI@Ovid. 2019; JBI3727.

32. Slade S. Evidence Summary. Delirium in Critical Care Settings: Screening and Assessment. The Joanna Briggs Institute EBP Database, JBI@Ovid. 2020; JBI5419.

33. Marin T. Evidence Summary. Postoperative Delirium (Older People): Prevention and Management. The Joanna Briggs Institute EBP Database, JBI@Ovid. 2019; JBI3727.

34. Agency for Clinical Information (ACI), Delirium. Agency for Clinical Information. NSW. Available from: https://www.aci. health.nsw.gov.au/ data/assets/pdf file/0018/181701/AClDelirium-Brochure.pdf

35. Agency for Clinical Information (ACl). Care of confused Hospitalised older persons. Agency for Clinical Information. NSW. 2013. Available from: www.aci.health.nsw.gov.au/chops.

36. Harvey G, Kitson A. Implementing evidence-based practice in healthcare: a facilitation guide. London and New York: Routledge Taylor \& Francis Group; 2015.
37. Dogherty E, Harrison M, Graham I. Facilitation as a role and process in achieving evidence-based practice in nursing: a focused review of concept and meaning. Worldviews Evid Based Nurs. 2010; 7(2): 76-89.

38. Dogherty E, Harrison M, Baker C, Graham I. Following a natural experiment of guideline adaptation and early implementation: a mixed methods study of facilitation. Implement Sci. 2012; 7: 9.

39. Baloh J, Zhu X, Ward M. Types of internal facilitation activities in hospitals implementing evidence-based interventions. Health Care Manage Rev. 2018; 43(3): 229-37.

40. Lizarondo L, McArthur A. Strategies for effective facilitation as a component of an evidence-based clinical fellowship program. J Contin Educ Nurs. 2017; 48(10): 458-63.

41. Cranley L, Cummings G, Profetto-McGrath J, Toth F, Estabrooks C. Facilitation roles and characteristics associated with research use by healthcare professionals: a scoping review. BMJ Open. 2017; 7: e014384.

42. Dogherty E, Harrison M, Graham I, Vandyk A, Keeping-Burke L. Turning knowledge into action at the point-of-care: the collective experience of nurses facilitating the implementation of evidence-based practice. Worldviews Evid Based Nurs. 2013; 10(3): 129-39.

43. Hunt J, Curran G, Kramer T, Mouden S, Ward-Jones S, Owen R, et al. Partnership for implementation of evidence-based mental health practices in rural federally qualified health centers: theory and methods. Prog Community Health Partnersh. 2012; 6(3): 389-98.

44. Khan A, Boukrina O, Oh-Park M, Flanagan N, Singh M, Oldham $M$. Preventing delirium takes a village: systematic review and meta-analysis of delirium preventive models of care. J Hosp Med. 2019; 14(9): 558-64.

45. Rosen M, DiazGranados D, Dietz A, Benishek L, Thompson D, Pronovost $\mathrm{P}$, et al. Teamwork in healthcare: key discoveries enabling safer, high-quality care. Am Psychol. 2018; 73(4): 43350 .

46. Grossman F, Hasemann W, Graber A, Bingisser R, Kressig R, Nickel C. Screening, detection and management of delirium in the emergency department - a pilot study on the feasibility of a new algorithm for use in older emergency department patients: the modified Confusion Assessment Method for the Emergency Department (mCAM-ED). Scand J Trauma Resusc Emerg Med. 2014; 22: 19

47. Yanamadala M, Wieland D, Heflin M. Educational interventions to improve recognition of delirium: a systematic review. J Am Geriatr Soc. 2013; 61(11): 1983-93.

48. Wand A. Evaluating the effectiveness of educational interventions to prevent delirium. Australas J Ageing. 2011; 30(4): 175-85

49. Yevchak A, Fick D, Kolanowski A, Monroe T, Leviere A, Mion L. Implementing nurse-facilitated person-centered care approaches for patients with delirium superimposed on dementia in the acute care setting. J Gerontol Nurs. 2017; 43(12): 21-8.

50. Logan J. Recognising and managing delirium in patients receiving palliative and end of life care. Nurs Stand. 2018; 33(8): 63-8.

51. Stuck A, Clark MJ, Connelly C. Preventing intensive care unit delirium. Dimens Crit Care Nurs. 2011; 30(6): 315-20.

52. McCambridge J, Witton J, Elbourne D. Systematic review of the Hawthorne effect: new concepts are needed to study research participation effects. J Clin Epidemiol. 2014; 67: 267-77. 